\title{
Dual Edge-Fed Left Hand and Right Hand Circularly Polarized Rectangular Micro-Strip Patch Antenna for Wireless Communication Applications
}

\author{
${ }^{1}$ Dr. V. Prakasam, ${ }^{2}$ Dr. P. Sandeep \\ ${ }^{1}$ Vignan Institute of Technology and Science, India \\ Email: vprn2274@gmail.com \\ ${ }^{2}$ Vignan Institute of Technology and Science, India \\ Email: san9ap@gmail.com
}

\begin{abstract}
Presently a days the remote correspondence framework advancement requires the ease, low profile, insignificant weight radio wire improvement which is cultivated of proceeding with incredible introduction finished a wide recurrence range. The MSPA architecture has facilitated this forward thinking skills trend. Within this paper work a $4.85 \mathrm{GHz}$ circular polarization operating frequency is planned and simulated for RMSPA. The proposed antenna is capable of designing and inducing Left Hand Loop Polarization (LHCP) and Right Hand Loop Polarization (RHCP) using a cross-coupler that is directly attached to the micro-strip antenna to polarize the circular. The proposed paper work working recurrence is $4.85 \mathrm{GHz}$ which is essentially utilized for satellite interchanges, full-time satellite TV organizations. This working recurrence is the IEEE 802.11a variation $\mathrm{C}$ band recurrence and this $\mathrm{C}$ band recurrence is utilized in Wi-Fi gadgets and Radio LAN. The proposed FR-4 roundabout polarization rectangular miniature strip fix radio wire is $1.6 \mathrm{~mm}$ thick. The proposed rectangular micro strip fix radio wire is planned and mimicked utilizing CSTMWS (Computer Simulation Technology Micro Wave Studio) programming. The full or working recurrence of proposed radio wire presents at $4.85 \mathrm{GHz}$ for remote correspondences that gives $\mathrm{S}$ boundaries, data transmission and radiation example of Gain and directivity.
\end{abstract}

Keywords: Dual-fed, Micro Strip, Circular Polarization, FR-4, TV, LHCP, RHCP, CSTMWS, Gain, Bandwidth.

\section{Introduction}

A remote neighbourhood is a little space correspondence framework most prominent habitually utilized for interfacing at least two remote methodologies inside an inadequate arrangement [6]. WLANs follow the IEEE802.11 standards which has so far recorded the recurrence use in band i.e., 4.85 GHz. The proposed paper work contains of plan and recreation of high increase reception apparatuses for $4.85 \mathrm{GHz}$ and great data transmission at $4.85 \mathrm{GHz}$ working recurrence. The rudimentary WLAN development incorporates of the wired LAN arrangement, remote systems and a contact point which exhibitions as connection between the two. Higher the increase of the radio wire extra will be the assortment that can be ensured. Henceforth, high increase radio wires creation indispensable part in WLAN applications [8]. The proposed reception apparatus has great addition and transmission capacity. In translation of the above facts, we future the plan and re-enactment of high increase double took care of circularly enraptured rectangular miniature strip fix reception apparatus with left half and right half circularly polarization in the current work.

In the previous years, miniature strip radio wires frameworks are utilized in an enormous number of microwave correspondence applications because of the savvy structures of ease, similarity with incorporated circuits and loosened up manufacture. Typically, they are intended to invigorate either roundabout or straight enraptured waves. This paper is concentrated to plan and re-enactment double edge took care of a circularly enraptured reception apparatus at $4.85 \mathrm{GHz}$ for satellite correspondence applications. The hugest bit of leeway of utilizing round polarization is that independent of recipient direction, it will continually get a part of the sign.

\subsection{Circular Polarization}

The waves are peripatetic in helpful z-direction, the EF apparatuses in $\mathrm{x}$ direction and $\mathrm{y}$ direction are Ex $\rightarrow \mathrm{E}_{1} \sin (\omega \mathrm{t}-\beta \mathrm{z})$ and $\mathrm{Ey} \rightarrow \mathrm{E}_{2} \sin (\omega \mathrm{t}-\beta \mathrm{z}+\delta)$; where $\mathrm{E}_{1}$ and $\mathrm{E}_{2}$ are wave magnitudes linearly in $\mathrm{x}$ and $\mathrm{y}$ directions and $\delta$ is the angle of phase. Combining the above two equation we get total electric field expression $\mathrm{E} \rightarrow \mathrm{E}_{1} \sin$ $(\omega t-\beta z) a_{x}+E_{2} \sin (\omega t-\beta z+\delta) a_{y}$.

When this is polarized circularly, the $\mathrm{x}$ and y direction magnitudes are equal and $\delta= \pm \pi / 2$. For left hand circularly polarized wave, the phase angle $\delta$ is $\pi / 2$ and for right hand circularly polarized wave, the phase angle $\delta$ is $-\pi / 2$. 


\section{Design Aspects of Dual-Fed}

So as to plan any MSPA, we need some arrangement of boundaries. The above all else thing is working recurrence or reverberating recurrence $\mathrm{fO}$ or fr, in this proposed work the resounding recurrence is $4.85 \mathrm{GHz}$, the subsequent thing is stature of the substrate typically the tallness of the substrate $(\mathrm{h})$ is consider as $1.6 \mathrm{~mm}$ and third thing is sort of the substrate material, here the kind of the dielectric substrate material worth is 4.4.

\subsection{MSPA Formulation}

The program parameters of the planned RMSPA are Operating often ness, $\mathrm{f}_{\mathrm{r}}=4.85 \mathrm{GHz}$.

Generally, FR4 see varies from 4.3 to 4.7 , here the material perpetual of FR4 stratum, $\varepsilon_{\mathrm{r}}=4.4$ and $\mathrm{h}=1.6 \mathrm{~mm}$.

The patch width is

$$
W=\frac{c}{2 f_{r} \sqrt{\frac{\epsilon_{r}+1}{2}}}
$$

Where $\mathrm{c} \rightarrow 3^{\times} 10^{11} \mathrm{~mm}$

The length of the patch antenna is $L=L_{\text {eff }}-2 \times \Delta L$

Where, Effective length, $L_{\text {eff }}=\frac{c}{2 f_{r} \sqrt{\varepsilon_{\text {reff }}}}$

Where Effective Dielectric Constant,

The Length Extension,

$$
\epsilon_{\text {reff }}=\frac{\epsilon_{r}+1}{2}+\frac{\epsilon_{r}-1}{2}\left[1+12 \frac{h}{W}\right]^{-1 / 2}
$$

$$
\Delta L=0.412 h \times\left\{\frac{\left(\epsilon_{\text {reff }}+0.3\right)\left(\frac{W}{h}+0.264\right)}{\left(\epsilon_{\text {reff }}-0.258\right)\left(\frac{W}{h}-0.8\right)}\right\}
$$

Determine the ground plane width and lengths

- $\quad$ Length of Ground plane, $L_{g} \rightarrow 2 * L$

- Width of Ground plane, $W_{g} \rightarrow 2 * W$

\subsection{MSPA Manual Calculation}

The calculation of proposed rectangular patch width is

$$
\begin{aligned}
& W=\frac{c}{2 f_{r} \sqrt{\frac{\epsilon_{r}+1}{2}}}=\frac{3 \times 10^{11}}{2 \times 4.85 \times 10^{9} \sqrt{\frac{4.4+1}{2}}} \\
& W=\frac{c}{2 f_{r} \sqrt{\frac{\epsilon_{r}+1}{2}}}=18.83 \mathrm{~mm}
\end{aligned}
$$

The calculation of $\mathrm{h} / \mathrm{W}$ and $\mathrm{W} / \mathrm{h}$ are

$$
\frac{h}{W}=\frac{1.6 \mathrm{~mm}}{18.83 \mathrm{~mm}}=0.085
$$$$
\text { And } \frac{W}{h}=\frac{1}{\frac{h}{W}}=\frac{1}{0.085}=11.763
$$

The calculation of effective dielectric constant is

$$
\begin{aligned}
& \epsilon_{\text {reff }}=\frac{\epsilon_{r}+1}{2}+\frac{\epsilon_{r}-1}{2}\left[1+12 \frac{h}{W}\right]^{-1 / 2} \\
& \epsilon_{\text {reff }}=\frac{4.4+1}{2}+\frac{4.4-1}{2}\left[1+12 \frac{1.6 \mathrm{~mm}}{18.83 \mathrm{~mm}}\right]^{-1 / 2} \\
& \epsilon_{\text {reff }}=3.896
\end{aligned}
$$


J. Sustain. Wireless Syst., vol. 02, no. 3, pp. 107-117

https://doi.org/10.36548/jsws.2020.3.001

The calculation of length extension is

$$
\begin{aligned}
& \Delta L=0.412 h \times\left\{\frac{\left(\epsilon_{\text {reff }}+0.3\right)\left(\frac{W}{h}+0.264\right)}{\left(\epsilon_{\text {reff }}-0.258\right)\left(\frac{W}{h}-0.8\right)}\right\} \\
& \Delta L=0.412 \times 1.6 \mathrm{~mm} \times\left\{\frac{(3.896+0.3)(11.763+0.264)}{(3.896-0.258)(11.763-0.8)}\right\} \\
& \Delta L=0.834 \mathrm{~mm}
\end{aligned}
$$

The calculation of effective length is

$$
\begin{aligned}
& L_{e f f}=\frac{c}{2 f_{r} \sqrt{\varepsilon_{\text {reff }}}}=\frac{3 \times 10^{11} \mathrm{~mm}}{2 \times 4.85 \times 10^{9} \times \sqrt{3.896}} \\
& L_{\text {eff }}=15.668 \mathrm{~mm}
\end{aligned}
$$

The calculation of proposed patch length is

$$
\begin{aligned}
& L=L_{\text {eff }}-2 \times \Delta L \\
& L=15.668 \mathrm{~mm}-2 \times 0.834 \mathrm{~mm}=14.0005 \mathrm{~mm}
\end{aligned}
$$

\subsection{RMSPA Design Parameters}

The table 1 shows the plan particular of round captivated rectangular micro strip fix cluster reception apparatuses with corporate feed organization.

\begin{tabular}{|l|l|} 
Table 1. RMSPA Specifications \\
\begin{tabular}{|l|l|}
\hline Description \& Short Name & VALUE \\
\hline Operating frequency $\left(\mathrm{f}_{\mathrm{r}}\right.$ or $\left.\mathrm{f}_{\mathrm{o}}\right)$ & $4.85 \mathrm{GHz}$ \\
\hline Dielectric Constant $\left(\varepsilon_{\mathrm{r}}\right)$ & 4.4 \\
\hline Width of the patch $(\mathrm{W})$ & $18.83 \mathrm{~mm}$ \\
\hline Length of the patch $(\mathrm{L})$ & $14.00 \mathrm{~mm}$ \\
\hline Loss tangent $(\tan \delta)$ & $0 \mathrm{~mm}$ \\
\hline Feed line width $\left(\mathrm{W}_{\mathrm{f}}\right)$ & $3.102 \mathrm{~mm}$ \\
\hline Feed line length $\left(\mathrm{L}_{\mathrm{f}}\right)$ & $8.302 \mathrm{~mm}$ \\
\hline Input impedance & $50 \mathrm{ohms}$ \\
\hline
\end{tabular}
\end{tabular}

\subsection{Directional Coupler}

The outlet line mixture coupler is a 3 -dB directional coupler with a stage move of 90 degrees between through yields and coupled port and port number 4 is separated port. The mathematical deliveries are:

$$
\begin{aligned}
& \frac{\mathrm{w}_{2}}{\mathrm{~h}_{2}}=\left\{\begin{array}{c}
\frac{2}{\pi}\left[\mathrm{B}-1-\ln (2 \mathrm{~B}-1)+\frac{\varepsilon_{\mathrm{r}}-1}{2 \varepsilon_{\mathrm{r}}}\left\{\ln (\mathrm{B}-1)+0.39-\frac{0.61}{\varepsilon_{\mathrm{r}}}\right\}\right] \\
\frac{8 \mathrm{e}^{\mathrm{A}}}{\mathrm{e}^{2 \mathrm{~A}}-2} ; \frac{\mathrm{w}_{2}}{\mathrm{~h}_{2}}<2
\end{array}\right. \\
& \mathrm{B}=\frac{377 \pi}{2 \mathrm{Z}_{0} \sqrt{\varepsilon_{\mathrm{r}}}} ; \frac{\mathrm{w}_{2}}{\mathrm{~h}_{2}}>2 \\
& ; 1=\frac{90^{\circ}\left(\pi \times 180^{\circ}\right)}{\sqrt{\varepsilon_{\mathrm{reff}}} \times \mathrm{k}_{0}} ; k_{0}=\frac{2 \pi f}{c}
\end{aligned}
$$

Where $1 \rightarrow$ hybrid length. The branch line coupler s-matrix is given by

$$
[S]=-\frac{1}{\sqrt{2}}\left[\begin{array}{llll}
0 & j & 1 & 0 \\
j & 0 & 0 & 1 \\
1 & 0 & 0 & j \\
0 & 1 & j & 0
\end{array}\right]
$$


J. Sustain. Wireless Syst., vol. 02, no. 3, pp. 107-117

https://doi.org/10.36548/jsws.2020.3.001

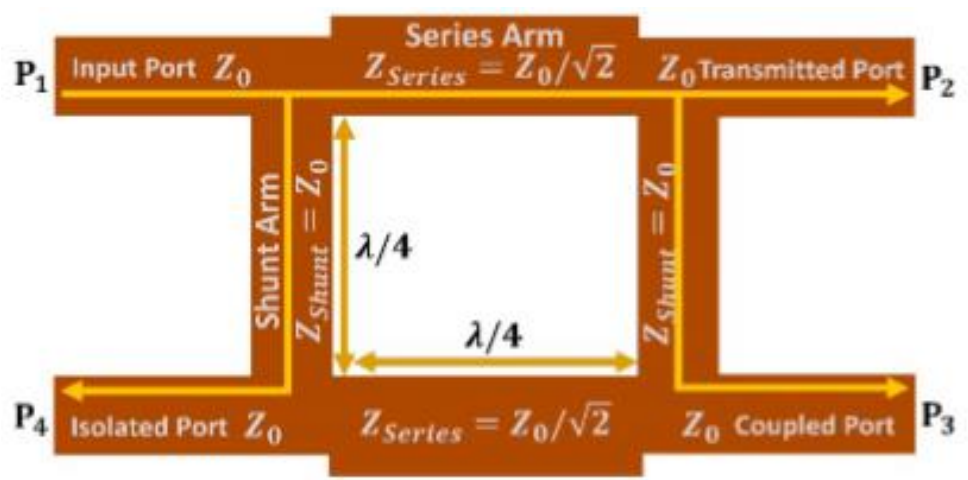

Figure 1. Geometry of a conventional branch line coupler.

\section{Design of MSA Polarization}

In circular polarization, the energy can be radiated into two planes that are horizontal plane and vertical plan. The left hand roundabout polarization can be characterized as two signals or waves has equivalent size qualities yet $90^{\circ}$ stage move. In left hand round polarization wave is turning in hostile to clock insightful or counter clockwise bearing. Then again, in the correct hand roundabout polarization the wave is pivoting clockwise way.

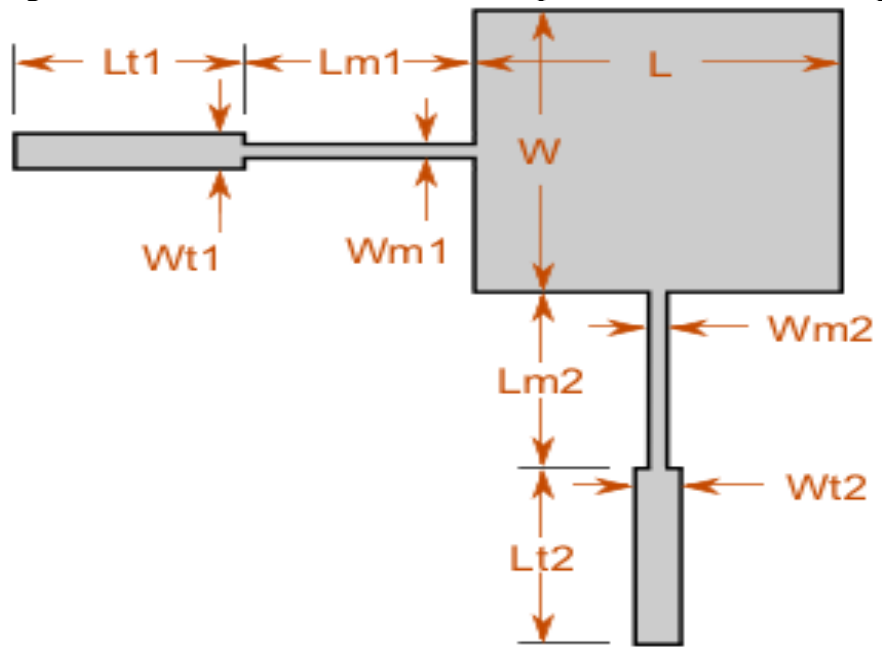

Figure 2. Geometry of the proposed dual-fed antenna.

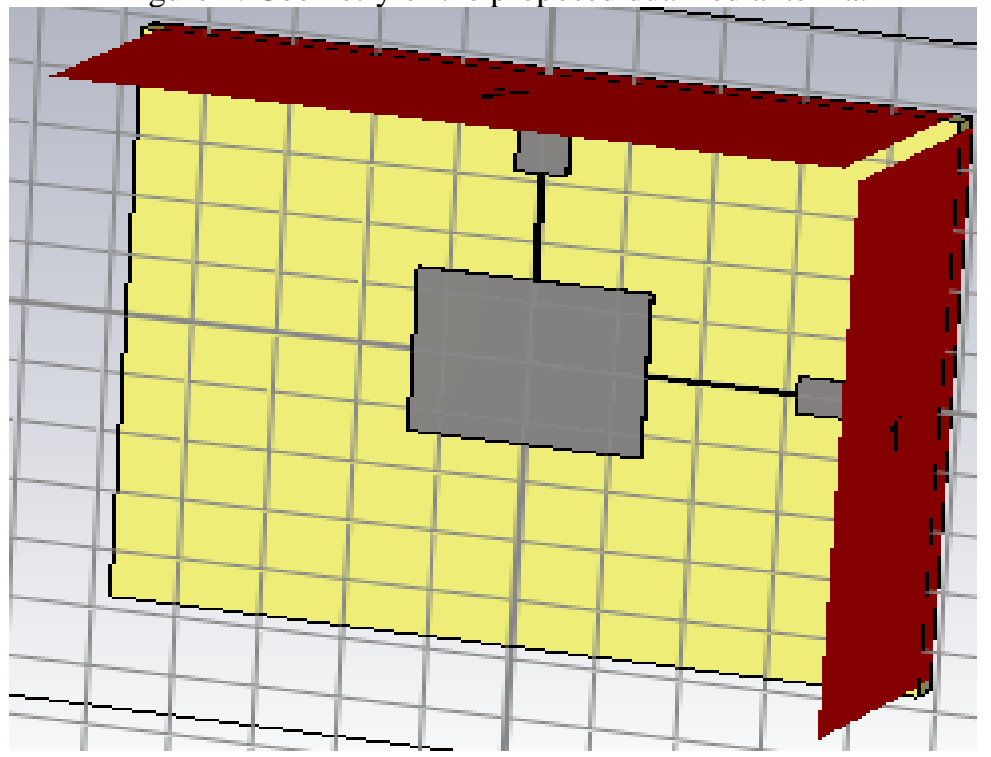

Figure 3. 3D view Dual-Edge-Fed Left Hand Circularly Polarized RMSPA. 
J. Sustain. Wireless Syst., vol. 02, no. 3, pp. 107-117

https://doi.org/10.36548/jsws.2020.3.001

Table 2. Proposed Dual-Fed Antenna Specifications

\begin{tabular}{|l|l|}
\hline Description \& Short Name & VALUE \\
\hline Patch Width (W) & $18.83 \mathrm{~mm}$ \\
\hline Patch Length (L) & $14.00 \mathrm{~mm}$ \\
\hline Port1 length (Lm1) & $8.841 \mathrm{~mm}$ \\
\hline Port1 width (Wm1) & $0.2051 \mathrm{~mm}$ \\
\hline Port1 feed length (Lt1) & $8.214 \mathrm{~mm}$ \\
\hline Port1 feed width (Wt1) & $3.059 \mathrm{~mm}$ \\
\hline Port2 length (Lm2) & $8.841 \mathrm{~mm}$ \\
\hline Port2 width (Wm2) & $0.2051 \mathrm{~mm}$ \\
\hline Port2 feed length (Lt2) & $8.214 \mathrm{~mm}$ \\
\hline Port2 feed width (Wt2) & $3.059 \mathrm{~mm}$ \\
\hline
\end{tabular}

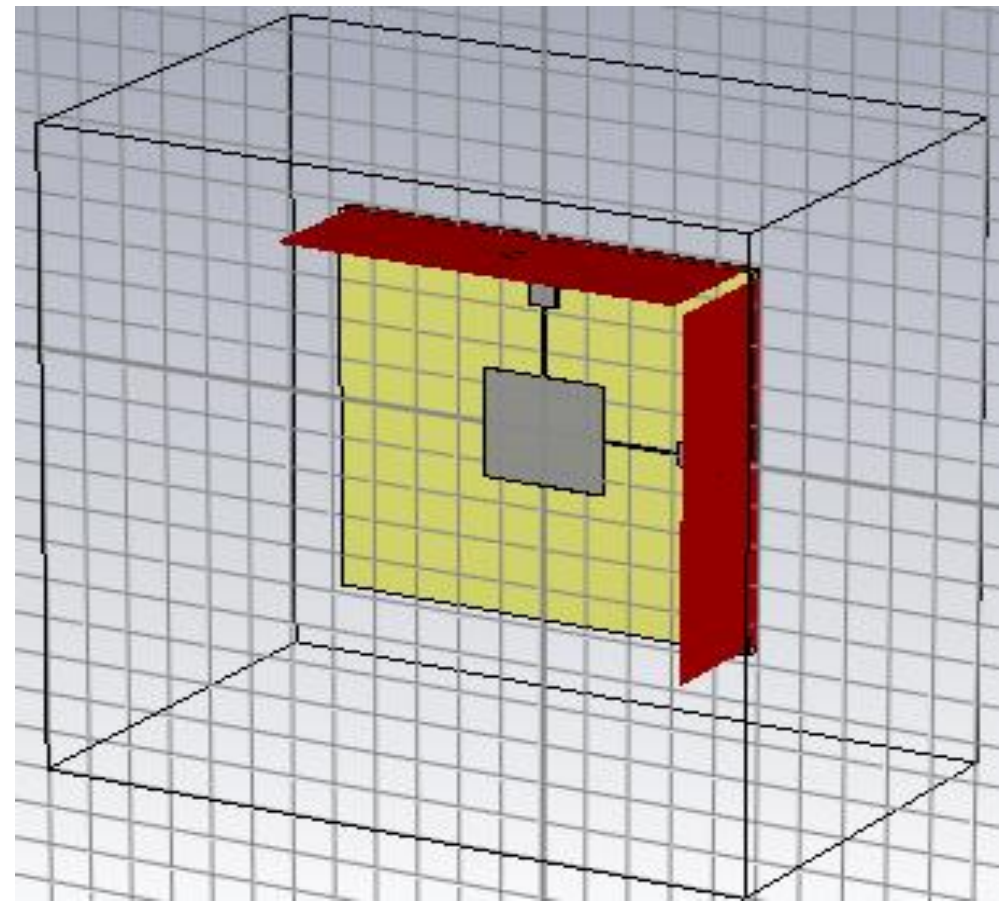

Figure 4. 3D view Dual-Edge-Fed Right Hand Circularly Polarized RMSPA.

From the geometrical design view $\mathrm{Lm} 1$ is the port1 length which is the length of matching transmission line, $\mathrm{Wm} 2$ is the width of port 1 which is the transmission line width, $\mathrm{Lt} 1$ is the port 1 feed which is transmission line feed, $\mathrm{Lm} 2$ is the port 2 length which is the length of matching transmission line, Wm2 is the width of port 2 which is the transmission line width, Lt2 is the port 2 feed which is transmission line feed.

The left-hand circular polarization and right hand circular polarization rectangular patch width and length are same that are $18.83 \mathrm{~mm} \times 14.00 \mathrm{~mm}$. length of port 1 and port 2 are same. The 3D perspective on double edgetook care of left hand round polarization rectangular miniature strip fix radio wire as appeared in figure 3 . The figure 4 shows the double edge-took care of right hand roundabout polarization rectangular miniature strip fix reception apparatus $3 \mathrm{D}$ see.

\section{Simulation Results And Discussion}

Present days, the decoration and representation results are very valuable travail to reckon the action of system through software model tools before the sincere abstraction executing. CST MWS simulator software supports to process the value of untruth since exclusive the tentacle through the large execution would be invented.

Here, reproduce and examine the proposed reception apparatus plan execution, the recreation aftereffects of s-boundary, transmission capacity, addition and directivity are assessed at $4.85 \mathrm{GHz}$ working recurrence. The proposed radio wire has FR-4 epoxy substrate, which dielectric consistent 4.4, thick ness of the substrate is 1.6 $\mathrm{mm}$ and $0 \mathrm{~mm}$ misfortune digression. In this administrative work, we select the base recurrence go is $3 \mathrm{GHz}$ and 
greatest recurrence run is $7 \mathrm{GHz}$. Superior the example area solver parameters that are Topology type is Hexahedral, Quality is $-40 \mathrm{~dB}$, Author Identify is all ports, Modality is all type, normalized to leaded impedance consider is $\mathbf{5 0} \mathrm{ohms}$ and finally depression the start add.

\subsection{S-Parameters}

The general representation of scattering parameter is $S_{\mathrm{ij}}$. In this general representation, the first subscript indicate the output of the port and second subscript indicate the input of the port. The hypothetical reflection coefficient worth ought to be not exactly - $10 \mathrm{~dB}$. In this administrative work the reflection coefficient (S11) esteem is $-15.985891 \mathrm{~dB}$ at $4.85 \mathrm{GHz}$, this return misfortune esteem conveyed at port 1 when the info is applied at port 1 . The inclusion misfortune (S21) esteem at port 2 is $-14.13546 \mathrm{~dB}$ at $4.85 \mathrm{GHz}$ when the info is applied at port 1 . As indicated by return plot or reflection coefficient plot for left hand roundabout polarization has magnificent incentive than $-10 \mathrm{~dB}$ in the chose working recurrence. The return misfortune plot of double edgetook care of LHCP is appeared in figure 5. From the LHCP return loss plot maximum return loss output value at port 1 is $-16.35 \mathrm{~dB}$ at $4.86 \mathrm{GHz}$ and at port 2 is $-14.497 \mathrm{~dB}$ at $4.84 \mathrm{GHz}$.

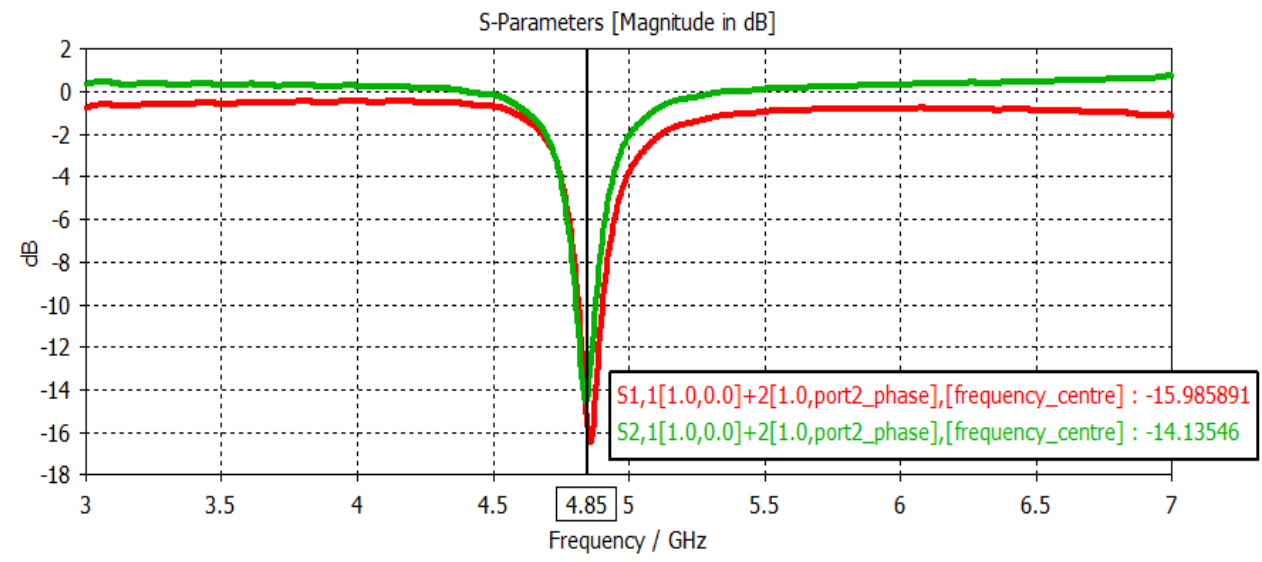

Figure 5. Return Loss plot of dual-edge-fed LHCP.

The proposed dual-edge-fed rectangular micro strip antenna simulation part is done. The reflection coefficient $\left(\mathrm{S}_{11}\right)$ value is $-14.135472 \mathrm{~dB}$ at $4.85 \mathrm{GHz}$, this return loss value delivered at port 1 when the input is applied at port 1. The insertion loss $\left(\mathrm{S}_{21}\right)$ value at port 2 is $-15.985903 \mathrm{~dB}$ at $4.85 \mathrm{GHz}$ when the input is applied at port 1 . According to return plot or reflection coefficient plot for right hand circular polarization has excellent value than $-10 \mathrm{~dB}$ in the selected operating frequency. The return loss plot of dual-edge-fed RHCP is shown in figure 6. From the RHCP return loss plot maximum return loss output value at port 1 is $-14.471 \mathrm{~dB}$ at $4.83 \mathrm{GHz}$ and at port 2 is $-16.363 \mathrm{~dB}$ at $4.86 \mathrm{GHz}$.

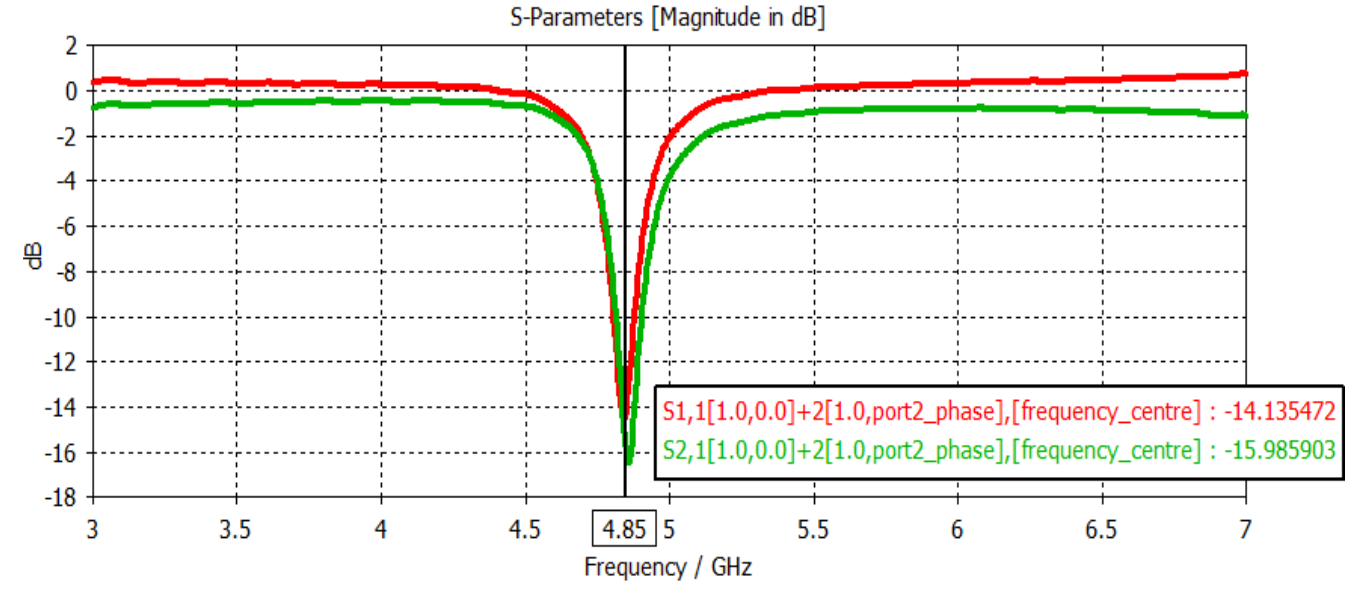

Figure 6. Return Loss plot of dual-edge-fed RHCP. 
J. Sustain. Wireless Syst., vol. 02, no. 3, pp. 107-117

https://doi.org/10.36548/jsws.2020.3.001

Table 3. Return Loss for LHSP and RHCP

\begin{tabular}{|l|l|l|l|l|}
\hline S.N & Frequency in GHz & \multirow{2}{*}{ Input } & \multicolumn{2}{|c|}{ Output in dB } \\
\cline { 4 - 5 } & & & Port 1 (RL) & Port 2 (IL) \\
\hline \multicolumn{5}{|c|}{ Left Hand Circular Polarization } \\
\hline 1 & 4.85 & Port 1 & -15.985891 & -14.13546 \\
\cline { 4 - 5 } & & -16.35 & -14.497 \\
\hline 2 & $4.86 \& 4.84$ & & -15.985903 \\
\hline 1 & 4.85 & Right Hand Circular Polarization \\
\hline 2 & $4.83 \& 4.86$ & -14.135472 & -16.363 \\
\cline { 5 - 5 }
\end{tabular}

\subsection{Bandwidth}

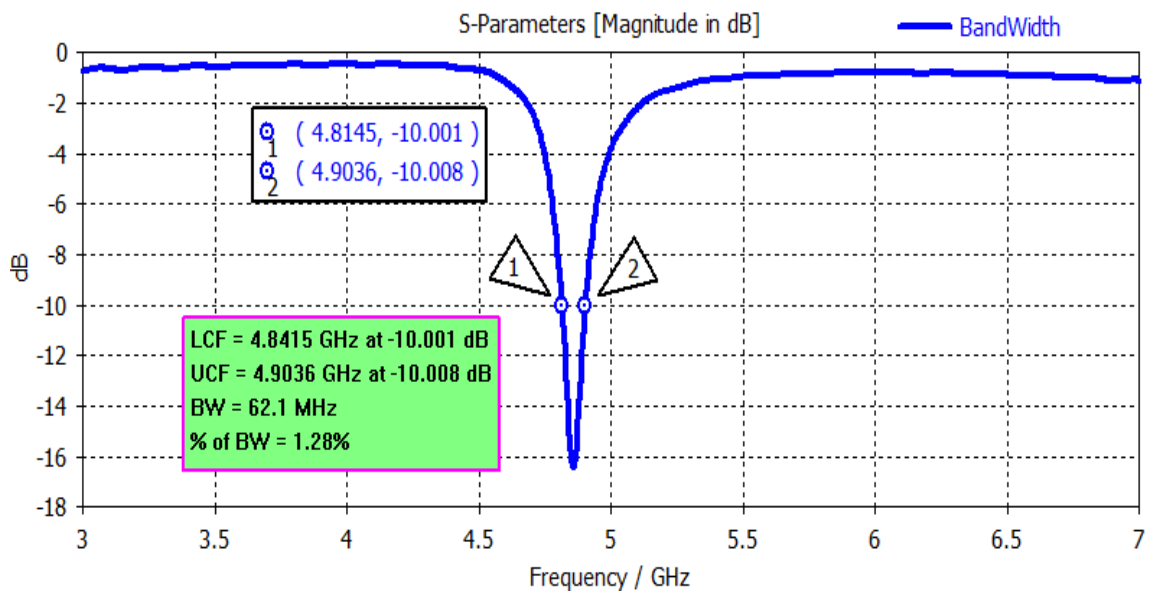

Figure 7. Bandwidth plot of dual-edge-fed LHCP.

The $\%$ of bandwidth is given by $B W=\frac{\left(f_{L-} f_{H}\right)}{f_{C}} X 100$. From the LHCP bandwidth strategy the arrival expiration value is $-15.985891 \mathrm{~dB}$ at $4.85 \mathrm{GHz}$, the lower cut-off frequency view is $4.8415 \mathrm{GHz}$ at $-10.001 \mathrm{~dB}$, upper cut-off frequency treasure is $4.9036 \mathrm{GHz}$ at $-10.008 \mathrm{~dB}$ and bandwidth and \% of bandwidth is $62.1 \mathrm{MHz}$ and $1.2804 \%$. The bandwidth plot of dual-edge-fed port sailor advertisement polarization micro undress repair antenna as shown in amount 7.

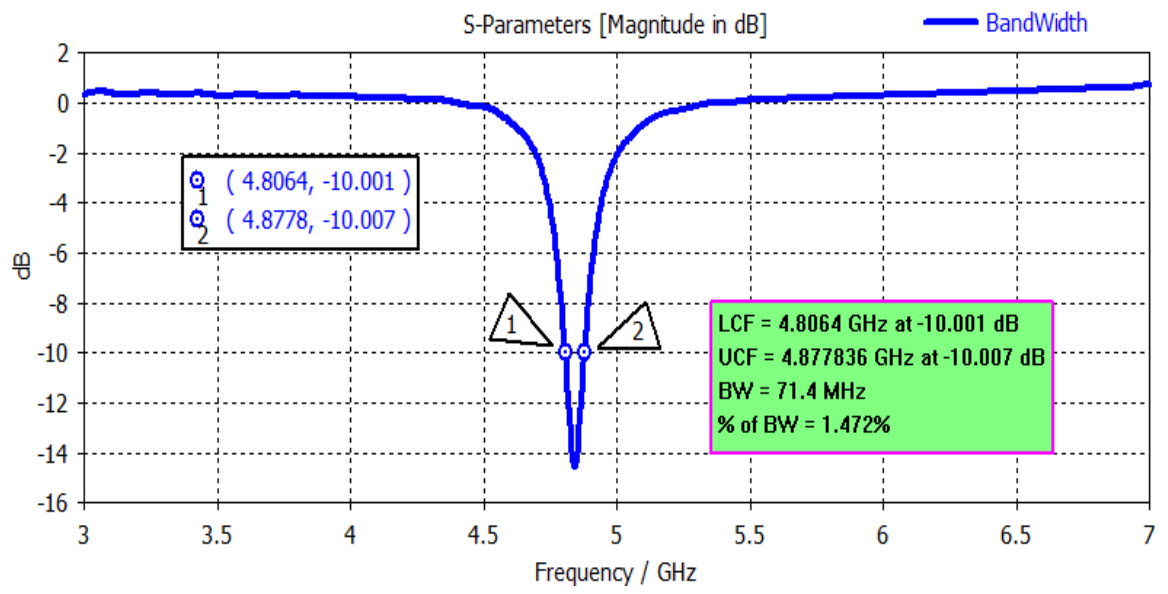

Figure 8. Bandwidth plot of dual-edge-fed RHCP.

From the RHCP bandwidth plot the return loss value is $-14.135472 \mathrm{~dB}$ at $4.85 \mathrm{GHz}$, the LCF frequency $\rightarrow 4.8064 \mathrm{GHz}$ at $-10.001 \mathrm{~dB}$, UCF frequency $\rightarrow 4.8778 \mathrm{GHz}$ at $-10.007 \mathrm{~dB}$ and BW and $\%$ of BW is $71.4 \mathrm{MHz}$ and $1.4722 \%$. The BW plot of dual-edge-fed right hand circular polarization MSPA as shown in figure 8 . 
J. Sustain. Wireless Syst., vol. 02, no. 3, pp. 107-117

https://doi.org/10.36548/jsws.2020.3.001

Table 4. Band Width and \% of BW for LHSP and RHCP

\begin{tabular}{|l|l|l|l|l|}
\hline S.N & Resonant Frequency & Type of Circular Polarization & Band Width & \% of BW \\
\hline 1 & \multirow{2}{*}{$4.85 \mathrm{GHz}$} & Left Hand & $62.1 \mathrm{MHz}$ & $1.2804 \%$ \\
\cline { 3 - 5 } 2 & & Right Hand & $71.4 \mathrm{MHz}$ & $1.4722 \%$ \\
\hline
\end{tabular}

\subsection{Smith Chart}

The smith outline plot of double edge-took care of left hand and right hand round polarization micro strip fix reception apparatus as appeared in figure 9.

\section{S-Parameters [Impedance View]}

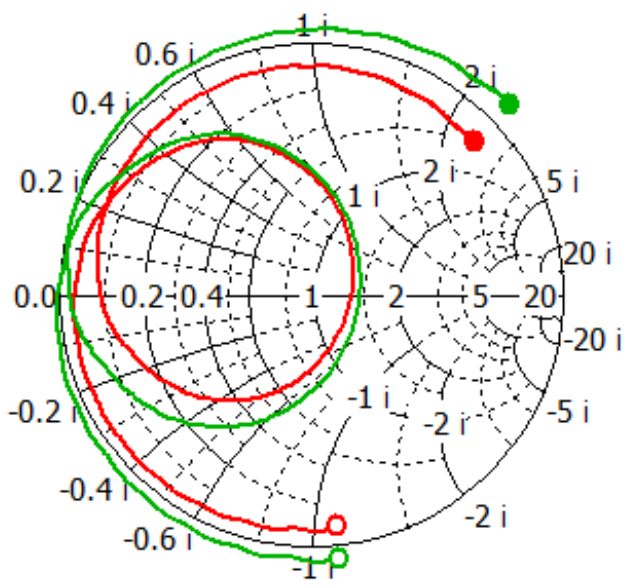

\section{S-Parameters [Impedance View]}

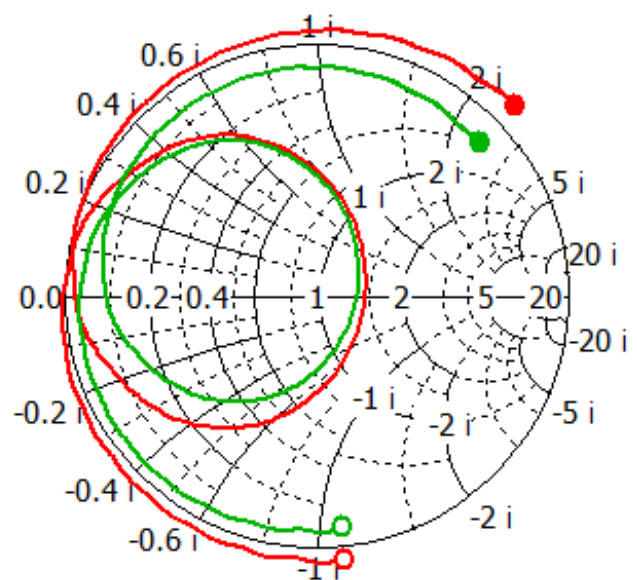

Figure 9. Smith chart plot of dual-edge-fed LHCP and RHCP.

\subsection{Far Field Gain and Directivity}
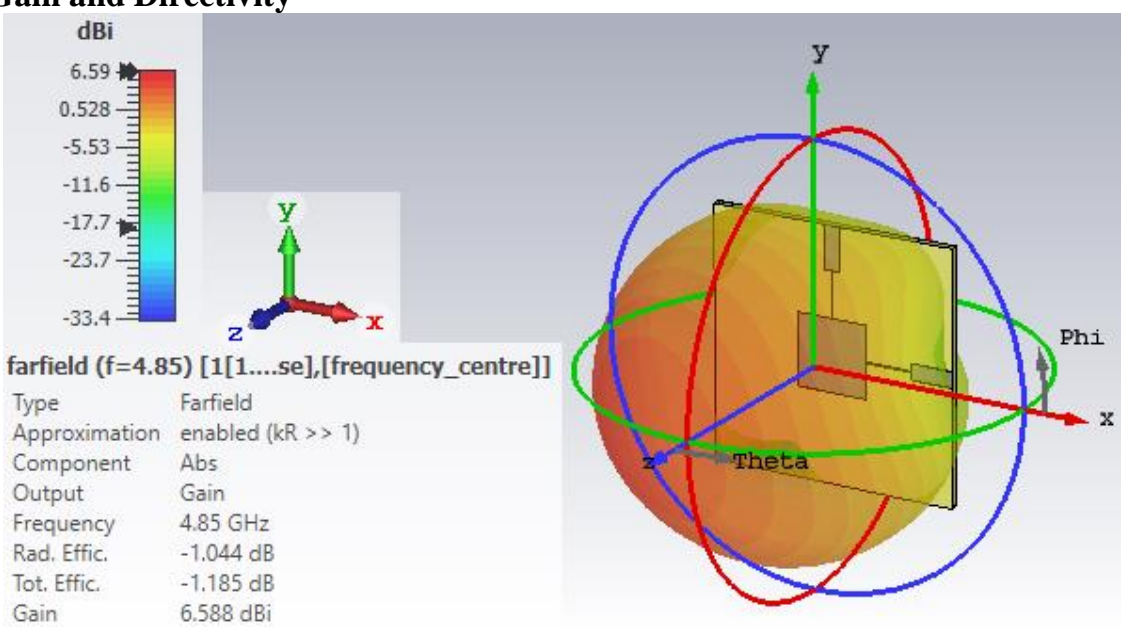

Figure 10. 3D Far Field Gain Pattern for dual-edge-fed LHSP.

The 3D far field gain radiation example and directivity radiation example of double edge-took care of left hand round polarization and right half-roundabout polarization miniature strip fix reception apparatus are appeared in figure 10 to figure 13 . As indicated by figure 10 , the far field gain is $6.59 \mathrm{dBi}$ at $4.85 \mathrm{GHz}$, which is the increase of LHCP. As per figure 11, the far field gain is $6.59 \mathrm{dBi}$ at $4.85 \mathrm{GHz}$, which is the increase of RHCP. According to figure 12, the far field directivity is $7.632 \mathrm{dBi}$ at $4.85 \mathrm{GHz}$, which is the directivity of LHCP. According to figure 12, the far field directivity is $7.632 \mathrm{dBi}$ at $4.85 \mathrm{GHz}$, which is the directivity of RHCP. Observe the LHCP and RHCP figures, the simulated resultant gain and directivity value is same at the specified operating frequency. The proposed antenna gain and directivity is suitable for wireless communication requirements. 
J. Sustain. Wireless Syst., vol. 02, no. 3, pp. 107-117

https://doi.org/10.36548/jsws.2020.3.001

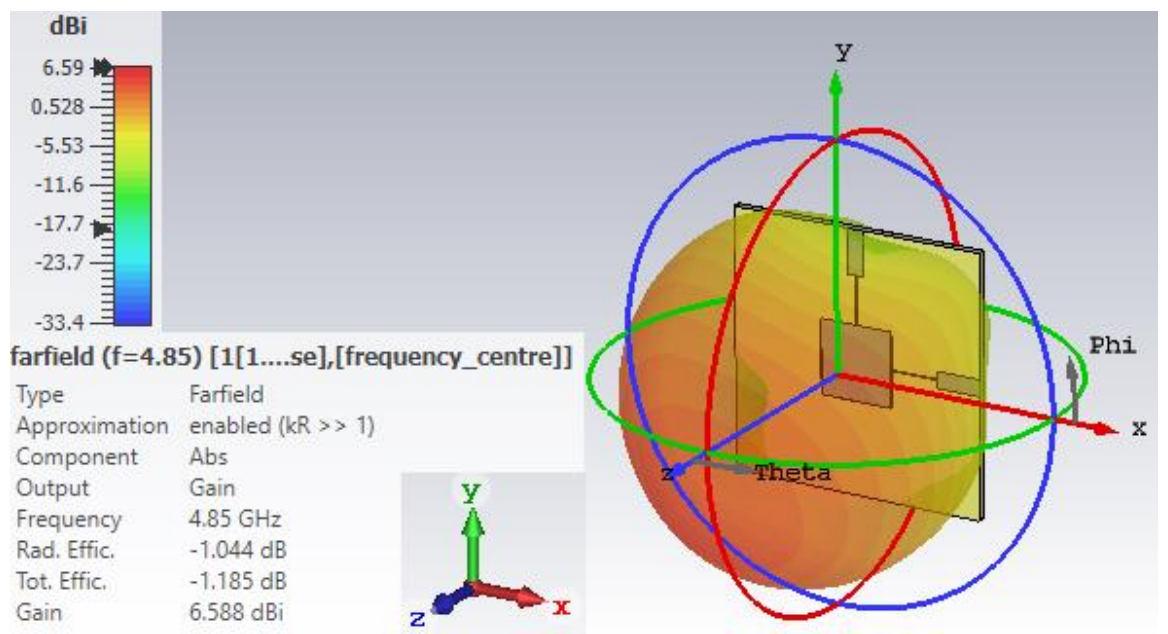

Figure 11. 3D Gain Pattern for dual-edge-fed RHSP.

The 2D far field gain radiation example and directivity radiation example of double edge-took care of left hand roundabout polarization and right half-round polarization miniature strip fix radio wire are appeared in figure 14 and figure 15 . According to figure 14 and figure 15, the main lobe magnitudes are $-15.0 \mathrm{deg}$. And -4.0 deg. In addition, side lobe magnitudes are $-12.7 \mathrm{~dB} \&-15.3 \mathrm{~dB}$.

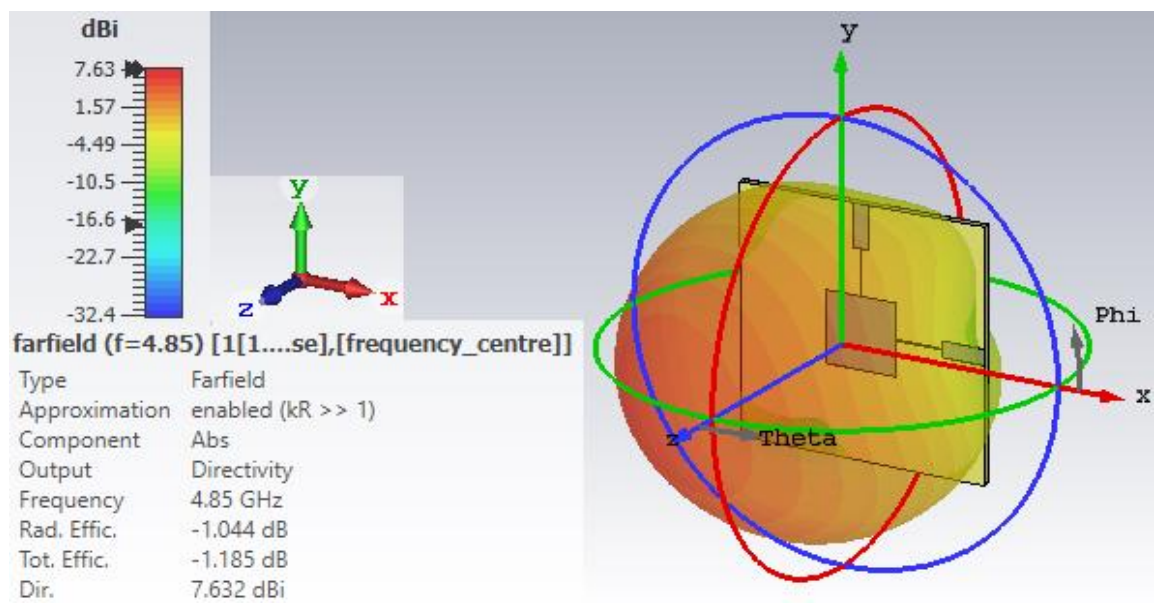

Figure 12. 3D Directivity Pattern for dual-edge-fed LHSP.

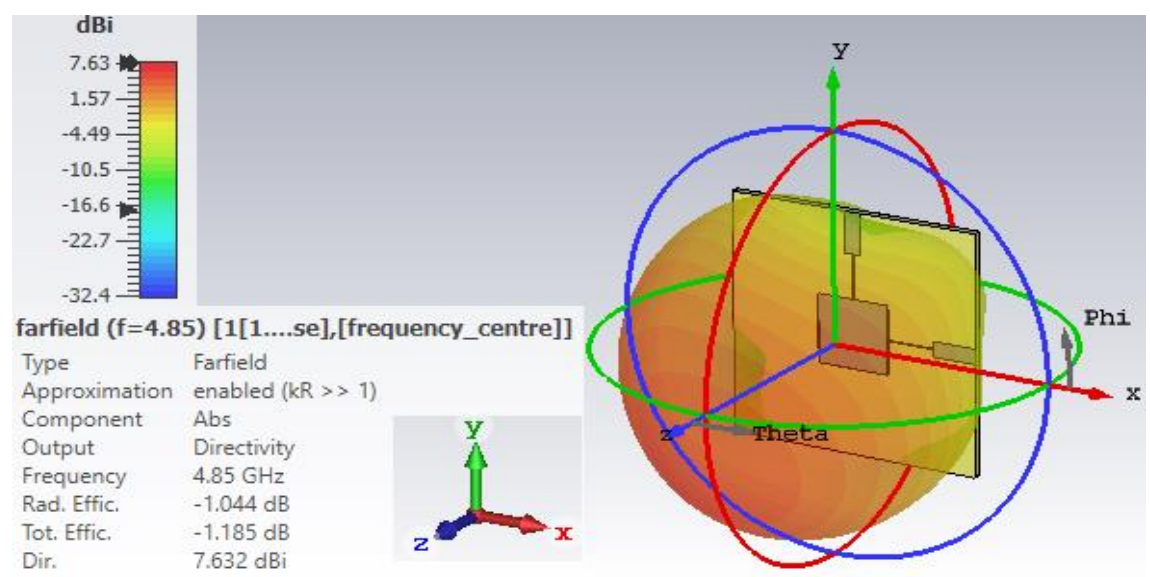

Figure 13. 3D Far Field Gain Pattern for dual-edge-fed RHSP. 
J. Sustain. Wireless Syst., vol. 02, no. 3, pp. 107-117

https://doi.org/10.36548/jsws.2020.3.001

Farfield Gain Abs (Phi=0)

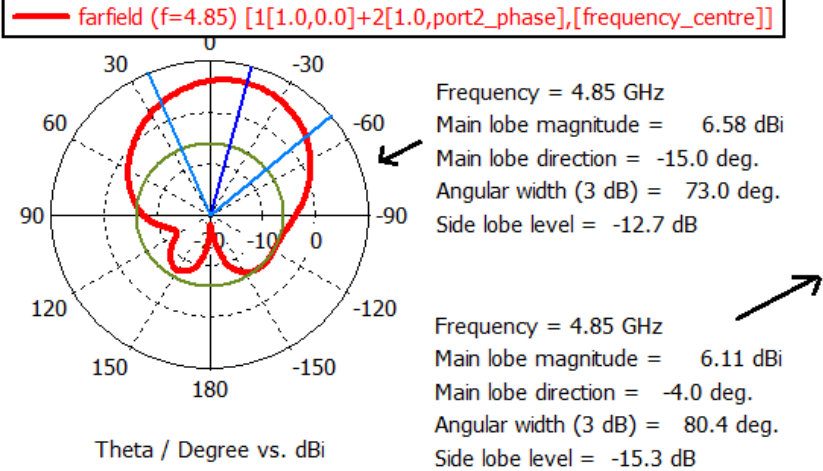

Farfield Gain Abs (Phi=0)

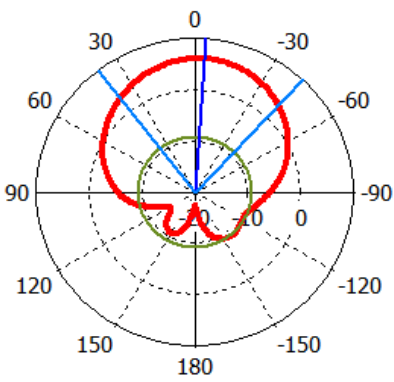

Theta / Degree vs. dBi

Figure 14. 2D Gain Pattern of LHCP and RHCP.

Farfield Directivity Abs (Phi $=0)$

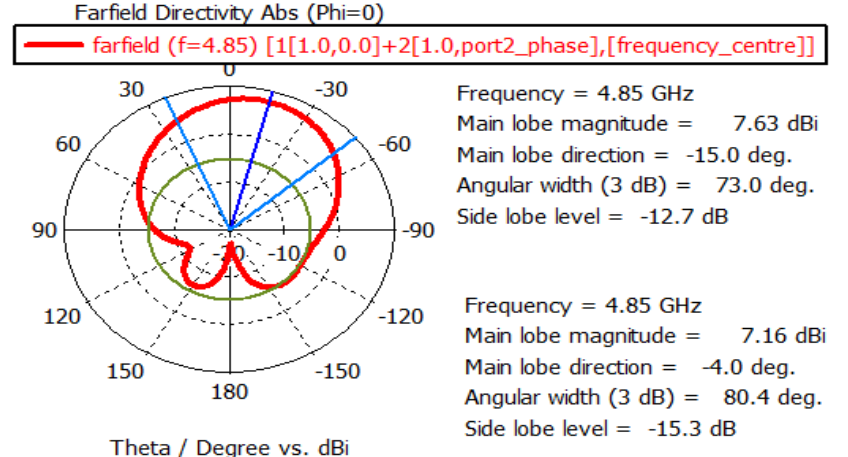

Figure 15. 2D Directivity Pattern of LHCP and RHCP.
Farfield Directivity Abs (Phi=0)

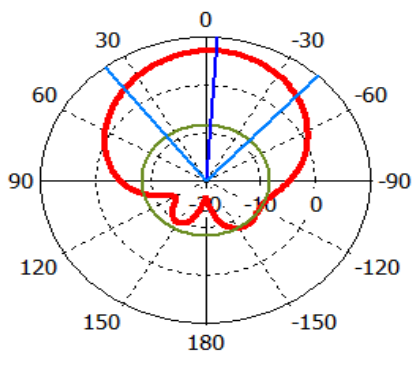

Theta / Degree vs. dBi

Table 5. Gain and Directivity for LHSP and RHCP

\begin{tabular}{|l|l|l|l|}
\hline S.N & \multirow{2}{*}{ Parameters } & \multicolumn{2}{|l|}{ Type of Circular Polarization } \\
\cline { 3 - 4 } & & Left Hand & Right Hand \\
\hline 1 & Gain & $6.59 \mathrm{dBi}$ & $6.59 \mathrm{dBi}$ \\
\hline 2 & Directivity & $7.63 \mathrm{dBi}$ & $7.63 \mathrm{dBi}$ \\
\hline 3 & Radiation Efficiency & $-1.044 \mathrm{~dB}$ & $-1.044 \mathrm{~dB}$ \\
\hline 4 & Total Efficiency & $-1.185 \mathrm{~dB}$ & $-1.185 \mathrm{~dB}$ \\
\hline
\end{tabular}

\section{Conclusion}

There are several categories of micro strip antenna arrangement that are stimulate a circular polarization. In this administrative work, we arranged a double edge-took care of captivated rectangular miniature strip reception apparatus. This proposed structure has been utilized for a remote correspondences framework at 4.85 $\mathrm{GHz}$, the dual-edge-fed left hand and right hand circular polarization micro strip antenna is effectively simulated and got the excellent simulation results at specified operating frequency. The return loss value is $-15.985891 \mathrm{~dB}$, Band width is $74.1 \mathrm{MHz}$, gain value is $6.59 \mathrm{dBi}$ and directivity is $7.632 \mathrm{dBi}$. According to this good results the circular polarization intellects varieties the proposed construction suitable for practical wireless communication applications needful circular polarization diversity.

\section{References}

[1] R. H. Chen, J. S. Row, Single-fed microstrip patch antenna with switchable polarization, IEEE Antennas and Wireless Propagation Letters, 56 (2008) 922-926.

[2] K. P. Ray, D. M. Suple, N. Kant, Suspended Hexagonal Microstrip Antennas for Circular Polarization. International Journal of Microwave and Optical Technology, Vol.5 No. 3 May 2010.

[3] R. Caso, A. Buffi, M. R. Pino, P. Nepa, A novel dual-feed slot-coupling feeding technique for circularly polarized patch arrays, IEEE Microw. Wireless Comp. Lett., 9 (2010) 183-186.

[4] Y. Ushijima, E. Nishiyama, M. Aikawa, Single-layer integrated microstrip array antenna for dual circular polarisation, IET Microw. Antennas Propag., 6 (2012) 962-968. 
[5] Pradeep Kumar, Neha Thakur: "Micro strip Antenna for $2.4 \mathrm{GHz}$ wireless applications". International journal of engineering Trends and Technology volume 4 issue 8(2013).

[6] Deepti Saxena1, Sweta Agarwal. "Low Cost E-Shaped Microstrip Patch Antenna Array for WLAN" International Journal of Advanced Research in Electrical, Electronics and Instrumentation Engineering. Vol. 3, Issue 4, April 2014.

[7] Satya Prakash Sinha, Mukesh Kumar, Jolis Gupta "Design Of 2x2 Shaped Rectangular Micro strip Array Antenna For GSM Application" International Journal of Scientific \& Engineering Research, Volume 6, Issue 5, May-2015.

[8] Prakasam, V. and Sandeep, P., Design and Analysis of $2 \times 2$ Circular Micro-Strip Patch Antenna Array for 2.4 GHZ Wireless Communication Application (November 22, 2018). International Journal for Innovative Engineering \& Management Research, Vol. 7, No. 12, Nov. 2018.

[9] Prakasam, V., \& Sandeep, P. (2019). Series-fed $3 \times 3$ square patch array for wireless communication applications using CSTMWS. International Journal of Engineering and Advanced Technology, 9(1), 5424-5429.

[10] V. Prakasam, K. R. Anudeep LaxmiKanth and P. Srinivasu, "Design and Simulation of Circular Microstrip Patch Antenna with Line Feed Wireless Communication Application," 2020 4th International Conference on Intelligent Computing and Control Systems (ICICCS), Madurai, India, 2020, pp. 279284, doi: 10.1109/ICICCS48265.2020.9121162.

[11] V. Prakasam, P. Sandeep and K. R. A. LaxmiKanth, "Rectangular Micro Strip Patch Array Antenna With Corporate Feed Network For Wireless Communication Applications," 2020 5th International Conference on Communication and Electronics Systems (ICCES), COIMBATORE, India, 2020, pp. 311-316, doi: 10.1109/ICCES48766.2020.9138028.

[12] V. Prakasam and N. Reddy, "Design and Simulation of Elliptical Micro strip Patch Antenna with Coaxial Probe Feeding for Satellites Applications Using Matlab," 2020 Fourth International Conference on ISMAC (IoT in Social, Mobile, Analytics and Cloud) (I-SMAC), Palladam, India, 2020, pp. 228-234, doi: 10.1109/I-SMAC49090.2020.9243472.

\section{Authors Biography}
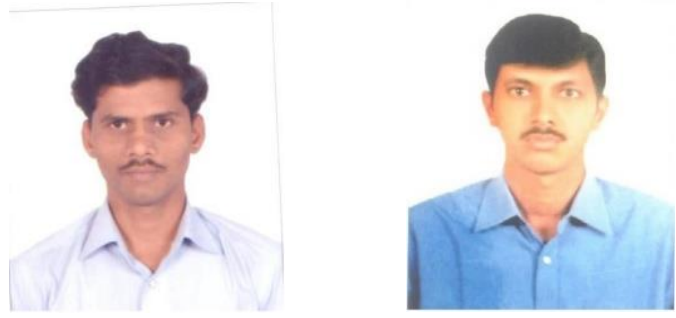

[1] Dr. V. PRAKASAM received B.Tech degree from JNTUA, M.Tech degree in VLSISD from JNTUK and completed p.hD. from SSSUTMS. He is currently an Assistant Professor in the department of Electronics and Communication Engineering at vignan institute of technology and sciences, deshumuki. His research interests Signal Processing, Image Processing, Microwave Engineering and RF Engineering.

[2] Dr. P.Sandeep received B.E degree from VTU, Belgaum, M.Tech degree in VLSID from Sathyabama University and completed p.hD. from SSSUTMS. He is currently an Assistant Professor in the department of Electronics and Communication Engineering at Vignan institute of technology and sciences, deshumuki. His research interests Signal processing, image processing, Analog Electronics engineering, Low Power and High Speed Systems and VLSI Design. 